\section{No association between breast-feeding and adult psychosis in two national birth cohorts}

\author{
S. J. LEASK, D. J. DONE, T. J. CROW, M. RICHARDS and P. B. JONES
}

Breast-feeding has been suggested as protective of cognitive development (Lucas $e t$ al, 1992; but see Gale \& Martyn, 1996; Malloy \& Berendes, 1998). Schizophrenia is preceded by childhood cognitive impairments (Jones et al, 1994; Crow et al, 1995), and McCreadie (1997) thought that breast-feeding might be a factor in the aetiology of schizophrenia. His figures seemed to show that those who were breast-fed as babies were two to three times less likely to develop schizophrenia in later life as those who were not, in a geographically defined population, using maternal recall of feeding histories in cases compared with their siblings, and published norms. Similar findings emerged from a case-control study by Peet et al (1997).

A plausible mechanism exists. Unlike cow's milk or most formula feeds, breastmilk contains large amounts of long-chain polyunsaturated fatty acids, such as docosahexaenoic acid (DHA), an important constituent of neuronal membranes. Lack of DHA might have adverse effects on development (Makrides et al, 1995; but see Innis et al, 1996), so that the lower postnatal DHA intake from formula feeds could explain the deviant cognitive and neurological development seen premorbidly in schizophrenia (Done et al, 1991; Dworkin et al, 1993; Jones et al, 1994).

\section{METHOD}

\section{Conclusions These findings provide no evidence of any effect of breast-feeding in protecting against the risk of later schizophrenia.}

Declaration of interest Funded by grants from the Stanley Foundation. and to plan for the needs of maternity services in the National Health Service due to be introduced 2 years later (Wadsworth, 1991). A random sample, stratified by social class, formed a cohort of 5362 individuals who have been followed to date: data have been collected on 20 occasions up to the age of 43, 11 times before the age of 16 , and 9 times since.

The 1958 National Child Development Study (NCDS) began life as The Perinatal Mortality Survey (Shepherd, 1985). It included $98 \%$ of births in mainland Britain during the week 3-9 March 1958. Five subsequent attempts have been made to trace and gather data on its members at age 7 , 11, 16, 23 and 33 (NCDS 1-5).

\section{Exposure: breast-feeding}

In both cohorts, details on perinatal feeding were obtained by the health visitor in an interview with the mother. In the NSHD this took place when the child was 2 years old. Breast-feeding was classified as not attempted, or stopped in the $1 \mathrm{st}, 2 \mathrm{nd}, 3 \mathrm{rd}$, 4th, 5th-7th, 8th-10th, or after the 10th month. In the NCDS the interview took place when the child was 7 years old, and breast-feeding was classified as not attempted, stopped in the first, or continued beyond the first month.

Data from the NSHD cohort were recoded to match the categories in the NCDS. The social class of the father at birth, and the gender of the child, were considered as potential confounders.

\section{Ooutcome: ascertainment of subjects with schizophrenia} NSHD (Jones et al, 1994)

By the age of 43 years 8 months, 81 of the members of the survey showed some evidence of a diagnosis of schizophrenia, use of regular neuroleptic medication, undefined severe mental illness or a psychiatric admission for unknown cause. Admissions were identified through a now discontinued national register, the Mental Health Enquiry, and reporting by survey members themselves. All available clinical material was scrutinised in order to determine whether these individuals met DSMIII-R criteria (American Psychiatric Association, 1987) for schizophrenia or schizoaffective disorder. 
Table I Breast-feeding status of children born in 1946 (National Survey of Health and Development (NSHD) cohort) and 1958 (National Child Development Study (NCDS) cohort), by gender and social class

\begin{tabular}{|c|c|c|c|c|c|c|c|c|c|c|c|c|}
\hline & \multicolumn{6}{|c|}{ NSHD } & \multicolumn{6}{|c|}{ NCDS } \\
\hline & \multicolumn{2}{|c|}{ Bottle-fed } & \multicolumn{2}{|c|}{ Breast-fed $<$ I month } & \multicolumn{2}{|c|}{ Breast-fed > I month } & \multicolumn{2}{|c|}{ Bottle-fed } & \multicolumn{2}{|c|}{ Breast-fed $<$ I month } & \multicolumn{2}{|c|}{ Breast-fed $>$ I month } \\
\hline & $n$ & (\%) & $n$ & (\%) & $n$ & (\%) & $n$ & (\%) & $n$ & (\%) & $n$ & (\%) \\
\hline \multicolumn{13}{|l|}{ Gender } \\
\hline Male & 555 & $(52.6)$ & 1142 & (53.7) & 632 & $(48.8)$ & 2404 & $(52.3)$ & 1842 & $(51.0)$ & 3199 & $(50.8)$ \\
\hline Female & 500 & $(47.4)$ & 984 & (46.3) & 663 & $(51.2)$ & 2191 & $(47.7)$ & 1769 & $(49.0)$ & 3096 & $(49.2)$ \\
\hline \multicolumn{13}{|c|}{ Social class } \\
\hline I-II & 214 & $(20.5)$ & 447 & $(21.2)$ & 333 & $(25.8)$ & 575 & $(13.9)$ & 503 & $(15.0)$ & 1254 & $(2 I .3)$ \\
\hline III & 529 & $(50.8)$ & $|12|$ & (53.2) & 653 & $(50.6)$ & 2498 & $(60.4)$ & 2066 & $(61.5)$ & 3565 & $(60.6)$ \\
\hline IV-V & 299 & $(28.7)$ & 540 & $(25.6)$ & 304 & $(23.6)$ & 1066 & $(25.8)$ & 790 & $(23.5)$ & 1060 & $(18.0)$ \\
\hline
\end{tabular}

\section{NCDS (Done et al, 1991)}

Patients discharged from psychiatric hospitals between 1974 and 1986 were identified from the Mental Health Enquiry, and where possible their case notes were obtained. These were used to fill in a Present State Examination (PSE) schedule, and from this input a CATEGO diagnosis (Wing et al, 1974). Cohort members were identified using NCDS data, and cohort members achieving a PSE diagnosis of 'S+' ('narrow schizophrenia') were included in the analysis.

\section{Statistics}

For the NSHD, a risk set of all the survey members alive in the UK at age 16 $(n=4746)$ was drawn from the stratified sample of 5362, as used in previous studies of schizophrenia and affective disorder in this sample (Jones et al, 1994; van Os et al, 1997).

For the NCDS, a risk set of all the survey members, with the recorded data on childhood breast-feeding and social class of the father at birth $(n=14501)$, was drawn from the total cohort of 18856 , and used in the analysis, in the same way as in previous studies in this data-set (Done et al, 1991; Crow et al, 1995).

In both cohorts we used a nested casecontrol design. We calculated odds ratios (ORs) and $95 \%$ confidence intervals (CIs) for exposure to breast-feeding in cases compared with controls, adjusted and unadjusted for confounding by gender and social class. Hypothesis tests used the $\chi^{2}$ statistic. All analyses were performed using SPSS for Windows, version 8.0.

Table 2 Breast-feeding status of cases and controls

\begin{tabular}{|c|c|c|c|c|c|c|c|c|c|c|}
\hline \multirow[t]{4}{*}{1946 NSHD } & \multicolumn{6}{|c|}{ Feeding } & \multicolumn{2}{|c|}{ Unadjusted odds ratio $(95 \% \mathrm{Cl})$} & \multicolumn{2}{|c|}{ Adjusted odds ratio $(95 \% \mathrm{Cl})$} \\
\hline & \multirow{2}{*}{\multicolumn{2}{|c|}{ Bottle-fed }} & \multirow{2}{*}{\multicolumn{2}{|c|}{$\begin{array}{l}\text { Breast-fed } \\
<I \text { month }\end{array}$}} & \multirow{2}{*}{\multicolumn{2}{|c|}{$\begin{array}{l}\text { Breast-fed } \\
>\text { I month }\end{array}$}} & \multirow{2}{*}{$\begin{array}{l}\text { Breast-fed } \\
<I \text { month }\end{array}$} & \multirow{2}{*}{$\begin{array}{l}\text { Bread-fed } \\
>I \text { month }\end{array}$} & \multirow{2}{*}{$\begin{array}{l}\text { Breast-fed } \\
<\mathrm{I} \text { month }\end{array}$} & \multirow{2}{*}{$\begin{array}{l}\text { Breast-fed } \\
>\text { I month }\end{array}$} \\
\hline & & & & & & & & & & \\
\hline & $n$ & (\%) & $n$ & (\%) & $n$ & (\%) & & & & \\
\hline Cases $(n=29)$ & 7 & $(24.1)$ & 5 & (I7.3) & 17 & $(58.6)$ & $1.36 \quad(0.43-4.3)$ & $0.89 \quad(0.37-2.2)$ & $1.35 \quad(0.43-4.3)$ & $0.86 \quad(0.36-2.1)$ \\
\hline Controls $(n=4447)$ & 1048 & $(23.6)$ & 549 & $(12.3)$ & 2850 & $(64.1)$ & & & & \\
\hline
\end{tabular}

Adjusted for gender and social class: $\chi^{2}(6, n=29)=5.8, P=0.44$.

Complete data available for 4476 individuals.

\begin{tabular}{|c|c|c|c|c|c|c|c|c|c|c|}
\hline \multirow[t]{4}{*}{1958 NCDS } & \multicolumn{6}{|c|}{ Feeding } & \multicolumn{2}{|c|}{ Unadjusted odds ratio $(95 \% \mathrm{Cl})$} & \multicolumn{2}{|c|}{ Adjusted odds ratio $(95 \% \mathrm{Cl})$} \\
\hline & \multirow{2}{*}{\multicolumn{2}{|c|}{ Bottle-fed }} & \multirow{2}{*}{\multicolumn{2}{|c|}{$\begin{array}{l}\text { Breast-fed } \\
<\text { I month }\end{array}$}} & \multirow{2}{*}{\multicolumn{2}{|c|}{$\begin{array}{l}\text { Breast-fed } \\
>\text { I month }\end{array}$}} & \multirow{2}{*}{$\begin{array}{l}\text { Breast-fed } \\
<\mathrm{I} \text { month }\end{array}$} & \multirow{2}{*}{$\begin{array}{l}\text { Bread-fed } \\
>\text { I month }\end{array}$} & \multirow{2}{*}{$\begin{array}{l}\text { Breast-fed } \\
<\text { I month }\end{array}$} & \multirow{2}{*}{$\begin{array}{l}\text { Breast-fed } \\
>\text { I month }\end{array}$} \\
\hline & & & & & & & & & & \\
\hline & $n$ & (\%) & $n$ & (\%) & $n$ & (\%) & & & & \\
\hline Cases $(n=29)$ & 7 & $(24.1)$ & 8 & $(27.6)$ & 14 & $(48.3)$ & $1.46 \quad(0.53-4.0)$ & $1.46 \quad(0.59-3.6)$ & $1.99 \quad(0.65-6.1)$ & $2.03 \quad(0.73-5.7)$ \\
\hline Controls $(n=14482)$ & 4588 & (3I.7) & 3603 & (24.9) & 6281 & $(43.4)$ & & & & \\
\hline
\end{tabular}

Adjusted for gender and social class: $\chi^{2}(5, n=27)=3.46, P=0.63$.

Complete data available for 13377 individuals. 


\section{RESULTS}

In the NSHD, information on perinatal feeding was available for 4703 (88\%) subjects; 30 subjects (20 male) met DSMIII-R criteria for schizophrenia or schizoaffective disorder, and for 29 of these data had been recorded on perinatal feeding, gender and social class.

The total number of births from 3-9 March 1958 in mainland Britain was 17414 , and information on perinatal feeding was available for $14501(83 \%)$ of these. Forty cohort members were identified who achieved a diagnosis of 'narrow schizophrenia' (PSE S+), of whom 29 (73\%) (14 male) had data recorded on perinatal feeding, and 27 on gender and social class as well.

Breast-feeding differed with gender and social class in both cohorts (Table 1 ). Associations between these two variables and schizophrenia have already been documented (Done et al, 1991; Jones et al, 1994), indicating that they were potential confounders of any association between breast-feeding and schizophrenia.

Numbers and percentages of cases and controls are shown in Table 2, stratified by cohort. The crude odds ratios showed no evidence of a protective effect of breast-feeding in either cohort; indeed, trends were in the other direction.

\section{DISCUSSION}

\section{No protective effect}

We have demonstrated no significant effect of breast-feeding as a protection against adult schizophrenia: if anything, our results contradict those of McCreadie (1997). The two analyses share low statistical power, but we are impressed by the consistency of our findings from two independent birth cohorts.

\section{Cohort v. case-control studies}

Our study benefits from two clearly-defined populations, with breast-feeding data collected in the same way for cases and controls during the same epoch in terms of feeding styles and fashions. In both populations, the data on breast-feeding were collected from mothers when their children were some years old ( 2 years in the NSHD, 7 years in the NCDS). However, this is preferable to the situation in a conventional case-control study, which requires accurate recall not only over $20-30$ years, but also

\section{CLINICAL IMPLICATIONS}

Choice of feeding method should not be made out of concern over adverse psychiatric consequences.

The consistency of results over two epidemiological samples strengthens this conclusion.

Findings from case-control studies remain vulnerable to selection and recall bias.

\section{LIMITATIONS}

Differences between the two population samples were not examined in any detail.

Details of exposure (e.g. types of non-breast milk) were unavailable.

Small numbers of cases; possible type 2 error (lack of power to detect small effects).

S. J. LEASK, P. B. JONES, University of Nottingham Department of Psychiatry; D. J. DONE, Psychology Division, University of Hertfordshire; T. J. CROW, Oxford University Department of Psychiatry; M. RICHARDS, National Survey of Health \& Development, University College, London

Correspondence: Dr Stuart J. Leask, School of Community Health Sciences, University of Nottingham, Duncan Macmillan House, Porchester Road, Nottingham NG3 6AA

(First received 20 October 1999, final revision 3 February 2000, accepted 10 February 2000)

with knowledge of the adult outcome; our data were gathered blind to this potential bias.

Comparing subjects' feeding histories from different epochs, as McCreadie was obliged to do, albeit at the same chronological age, is problematic. The differences in overall habits in the two cohorts (Table 1) provide evidence of a secular change. We used the definitions of schizophrenia in the two cohorts that were available to us. The similarity of the results from the two cohorts suggests that the difference in diagnosis is not relevant.

\section{Methodological issues}

Case ascertainment appears relatively unbiased in both cohorts. The total number of cases identified in each sample lie within the numbers which would be expected given their ages (Done et al, 1991; Jones et al, 1994). Thus, we do not think that we have preferentially identified groups with 'severe' schizophrenia and biased our findings.

Breast-feeding data were missing for a higher proportion of cases than of controls in the 1958 sample. However, we doubt that there is any serious, systematic bias, because of the similarity of the overall result compared with that for the earlier cohort, where exposure data were more complete.

Differences in national feeding patterns have already been noted (McCreadie, 1997), and might account for differences between studies; the majority of babies born in England in 1946 were initially breast-fed, even if this stopped within days, whereas data from Scotland in 1946 suggests that only half received any breast-milk at all. McCreadie compared his cases with national data derived from the NSHD before stratified sampling, whereas we used the stratified NSHD sample. This will have led to differences in the prevalence of breast-feeding but will not have biased our effects, because cases and controls came from the same population at risk, with equal baseline risk of inclusion. Another difference between our study and that of McCreadie is the fact that cases in both cohorts are effectively incident cases, whereas the Nithsdale (McCreadie's) sample is prevalent, biased towards 
chronic illness. Thus, while we can exclude a protective effect in terms of causation, the possibility remains of an effect on outcome. The positive associations are not without precedent (cf. Torrey et al, 1999), but lack significance in these data.

In summary, on the basis of an investigation in two national cohorts, the hypothesis that absence of breast-feeding contributes to the aetiology of schizophrenia is not supported. Significant findings in previous case-control studies are therefore likely to be Type I errors, due to methodological factors.

\section{ACKNOWLEDGEMENTS}

We gratefully acknowledge discussion with, and encouragement from, Professor Robin McCreadie, the support of Professor Mike Wadsworth and the NSHD team at University College, London, Dr Tony Gordon, Dr Peter Shepherd and the Social Statistics Research Unit at City University, London, and financial support from the Stanley Foundation.

\section{REFERENCES}

American Psychiatric Association (1987) Diagnostic and Statistical Manual of Mental Disorders (3rd edn, revised) (DSM-III-R). Washington, DC: APA
Crow, T. J., Done, D. J. \& Sacker, A. (1995) Childhood precursors of psychosis as clues to its evolutionary origins. European Archives of Psychiatry \& Clinical Neuroscience, 245, 61-69.

Done, D. J., Johnstone, E. C., Frith, C. D., et al (1991) Complications of pregnancy and delivery in relation to psychosis in adult life: data from the British Perinatal Mortality Survey. British Medical Journal, 302 1576-1580

Dworkin, R. H., Cornblatt, B. A., Friedmann, R., et al (1993) Childhood precursors of affective vs. social deficits in adolescents at risk for schizophrenia.

Schizophrenia Bulletin, 19, 563-577.

Gale, C. R. \& Martyn, C. N. (1996) Breast feeding dummy use, and adult intelligence. Lancet, 347, 1057 : comments, 1072-1075.

Innis, S. M., Nelson, C. M., Lwanga, D., et al (1996) Feeding formula without arachidonic acid and docosahexaenoic acid has no effect on preferential looking acuity or recognition memory in healthy fullterm infants at 9 months of age. American Journal of Clinical Nutrition, 64, 40-46.

Jones, P., Rodgers, B., Murray, R., et al (1994) Child developmental risk factors for schizophrenia in the 1946 birth cohort. Lancet, 344, 1398-1402.

Lucas, A., Morley, R., Cole, T. J., et al (1992) Breast milk and subsequent intelligence quotient in children born pre-term. Lancet, 339, 261-264.

Makrides, M., Neumann, M., Simmer, K., et al (1995) Are long-chain polyunsaturated fatty acids essential nutrients in infancy? Lancet, 345, 1463-1468.
Malloy, M. H. \& Berendes, H. (1998) Does breast feeding influence intelligence quotients at 9 and 10 years of age? Early Human Development, 50, 209-217.

McCreadie, R. G. (1997) The Nithsdale Schizophrenia Surveys |6. Breast-feeding and schizophrenia: preliminary results and hypotheses. British Journal of Psychiatry, I70, 334-337.

Peet, M., Poole, J. \& Laugharne, J. (1997) Infant feeding and the development of schizophrenia. Schizophrenia Research, 24, 255-256.

Shepherd, P. M. (1985) The National Child Development Study. An Introduction to the Background to the Study and the Methods of Data Collection (Working Paper No. I). London: Social Statistics Research Unit, City University.

Torrey, E. F., Rawlings, R. \& Yolken, R. H. (1999) The antecedents of psychoses: a case-control study of selected risk factors. Schizophrenia Research, 36, 57

van Os, J., Jones, P. B., Lewis, G., et al (1997) Developmental precursors of affective illness in a general population birth cohort. Archives of General Psychiatry, 54, 625-631.

Wadsworth, M. E. J. (1991) The Imprint of Time: Childhood, History and Adult Life. Oxford: Clarendon Press.

Wing, J. K., Cooper, J. E. \& Sartorius, N. (1974) The Measurement and Classification of Psychiatric Symptoms. Cambridge: Cambridge University Press. 